\title{
Caspase-9 pathway activation by inhibiting endogenous fibroblast growth factor signaling in human glioma cells
}

\author{
SHINTARO FUKUSHIMA ${ }^{1,2}$, SEIYA KATO ${ }^{2,3}$ MITSUHIDE MAEDA $^{1,2}$ and MINORU SHIGEMORI ${ }^{1}$ \\ Departments of ${ }^{1}$ Neurosurgery and ${ }^{2}$ Pathology, Kurume University, School of Medicine, Kurume; ${ }^{3}$ Division of Pathology \\ and Cell Biology, Graduate School and Faculty of Medicine, University of the Ryukyus, Okinawa, Japan
}

Received September 26, 2007; Accepted November 26, 2007

\begin{abstract}
The cell survival activity of human glioma cells is largely dependent on autocrine fibroblast growth factor (FGF) signaling. Caspases, a family of cysteine proteases, play an integral part in the execution phase of apoptosis. To better understand the mechanism of resistance to apoptosis in human glioma cells, we investigated the effect of a blockade of endogenous FGF signaling through the expression of the dominant negative type I FGF receptor (DNFGFR) in U251MG cells. The cells were infected with adenovirus vector expressing DNFGFR (AdDNFGFR) and apoptosis was semi-quantified by the terminal deoxynucleotidyl transferasemediated deoxyuridine triphosphate nick end-labeling (TUNEL) method and flow cytometric annexin V assay. The activation of caspase- $3,-8$, and -9 , the activation of Akt, a serine/threonine protein kinase, and the cleavage of poly(ADP-ribose) polymerase (PARP) were analyzed by immunoblotting. The infection with AdDNFGFR (multiplicity of infection of 200) induced marked apoptosis, along with a down-regulation of akt phosphorylation, and activation of caspase- 9 and -3 , but not -8 . By contrast, LacZ virus (a control) had minimal effects. The level of the cleaved form of PARP was increased in a time-dependent fashion, and this increase was inhibited by adding Z-DEVD-FMK, a caspase-3 inhibitor, and Z-LEHD-FMK, a caspase-9 inhibitor. Moreover, ultraviolet exposure $\left(100 \mathrm{~J} / \mathrm{m}^{2}\right)$ induced apoptosis and caspase-8, but not caspase- 9 , activation. Our data suggested that the induction of apoptosis through the inhibition of endogenous FGF signaling is caspase-9 pathwaydependent. The suppression of this or other specific antiapoptotic pathways may lead to genetic or pharmacological manipulations that favorably modulate the malignant behavior of human gliomas.
\end{abstract}

Correspondence to: Dr Seiya Kato, Division of Pathology and Cell Biology, Graduate School and Faculty of Medicine, University of Ryukyus, 207 Uehara, Nishihara, Okinawa 903-0215, Japan

E-mail: seikato@med.u-ryukyu.ac.jp

Key words: glioma, fibroblast growth factor, apoptosis, caspase, adenovirus vector

\section{Introduction}

Human gliomas show a poor prognosis even after multimodality treatment with extensive surgical resection and adjuvant therapies (1). Advances in molecular biology have revealed that the malignant behavior of gliomas is based on genetic or biomechanical abnormalities, suggesting a potential target for therapeutics (2). Most gliomas express both fibroblast growth factors (FGFs) and their high affinity receptors (FGFRs) and autocrine FGF signaling may play a pivotal role in the tumorigenesis of human gliomas (3-5). Autocrine FGF signaling is responsible not only for excess proliferation of glioma cells but also for cell survival promoting activity that has been shown to be distinct from mitogenic activity $(6,7)$. A neutralizing antibody against bFGF causes apoptosis in the human glioma cell lines U87MG and U251MG (8). Suramin has been shown to inhibit the binding of a variety of growth factors, including basic FGF (bFGF), to its cell surface receptors (9), and 1,3,6-naphthalenetrisulfonate, which represents a common chemical function of the suramins, not only inhibits proliferation, but also induces apoptosis in glioma cells (10).

We and others have reported that inhibiting endogenous FGF signaling by the exogenous expression of the antisense bFGF gene or oligonucleotide (7,11-13), the expression of dominant negative type I FGFR $(13,14)$, and the treatment with a 16-mer oligopeptide designed for conformational similarity to the putative receptor-binding site of bFGF (15), result in the growth suppression of human gliomas. Thus, it is expected that an intervention which can inhibit autocrine FGF and restore apoptotic signaling will have clinical potential. Ligand binding to the FGFR results in activation of the FGFR protein, which further activates downstream intracellular molecules such as Ras, mitogen-activated protein kinases (MAPKs), phosphatidylinositol 3'-kinase (PI3K), and Akt (a serine/threonine protein kinase), which are essential for growth factor-induced proliferation, differentiation, and cell survival activities (16-19).

We have also reported that cross-talk between two major signaling pathways, the Ras/MAPK and PI3K/Akt pathways, promotes cell survival activity in U251MG cells (14). Although the cell survival activity of human glioma cells may be largely dependent on the Akt activation $(14,20)$, a real executioner of apoptosis induced by inhibiting autocrine FGF signaling is unclear. 
Caspases are an evolutionarily conserved family of cysteine proteases that are responsible for diverse cellular functions, including apoptosis (21). Caspases can be divided into two main streams according to their functions: inflammatory (caspase-1, -4, -5, and -11) and apoptotic caspases. The former have been reported to play an important role in cytokine maturation. The latter can be further divided into initiators (caspase-2, -8, -9, -10, and -12) and effectors (caspase-3, -4, -7, and -12). Effector caspases are directly activated at the downstream of the initiator caspases, or activated dependent on the second messenger mechanism, and cleave certain cellular substrates to cause demolition of the cells (21). For example, these effector caspases cleave intracellular substrates, such as poly (ADP-ribose) polymerase (PARP), during the apoptotic process (22). Moreover, there are two major apoptotic pathways, the extrinsic (death receptor-mediated) and the intrinsic (mitochondrial, stress induced) pathways, and caspase- 8 and -9 have been shown to be the apical caspases in these distinct pathways, respectively $(23,24)$. At the downstream of growth factor-mediated Akt activation, several candidates promoting cell survival activity have been reported, such as BAD, a bcl-2 family member (25), FKHR-1, a forkhead family member (26), and caspase-9 (27). Herein, we studied the mechanism by which caspase activation in the human glioma cell line U251MG promotes apoptosis through blockade of endogenous FGF signaling.

\section{Materials and methods}

Recombinant adenovirus. The construction and preparation of an adenovirus vector expressing a kinase-defective mutant of type I FGFR (AdvDNFGFR; acts as a dominant negative FGFR) with a myc epitope were performed as described previously (28). The expression of mutated FGFR was confirmed by the expression of myc epitope with fluorescence microscopy or Western blotting using the 9E10 monoclonal antibody (American Type Culture Collection, Manassas, VA) (data not shown). The adenovirus vectors expressing Ras mutant RasN17 (AdvRasN17; acts as a dominant negative Ras) were the gift of Dr Joseph Nevins (Duke University, Durham, NC) (29). For the control, AdvLacZ encoding bacterial ß-galactosidase (a gift of Dr James Wilson, University of Pennsylvania, Philadelphia, PA) (30) was used in each experiment. Working stocks of viruses were prepared by large-scale infection of 293 cells (American Type Culture Collection) as previously described and stored in aliquots at $-80^{\circ} \mathrm{C}(31)$. Transfection efficiencies were tested by in situ $\mathrm{X}$-gal staining.

Cell culture and reagents. U251MG (Grade III glioma) was obtained as previously described $(13,14)$. Cells were maintained in Dulbecco's modified Eagle's medium (DMEM) (Nissui Pharmaceutical Co., Tokyo, Japan) containing 10\% fetal bovine serum (FBS) (Filtron Pty, Ltd., Brooklyn, Australia) together with antibiotics $(100 \mathrm{U} / \mathrm{ml}$ penicillin and $100 \mu \mathrm{g} / \mathrm{ml}$ streptomycin; Life Technologies, Grand Island, $\mathrm{NY})$ at $37^{\circ} \mathrm{C}$ in a humidified atmosphere of $5 \% \mathrm{CO}_{2}$ and trypsinized with trypsin-EDTA (Life Technologies). For the infection of adenovirus vectors, the cells were incubated for $24 \mathrm{~h}$ in serum-free DMEM containing the vectors at a
A
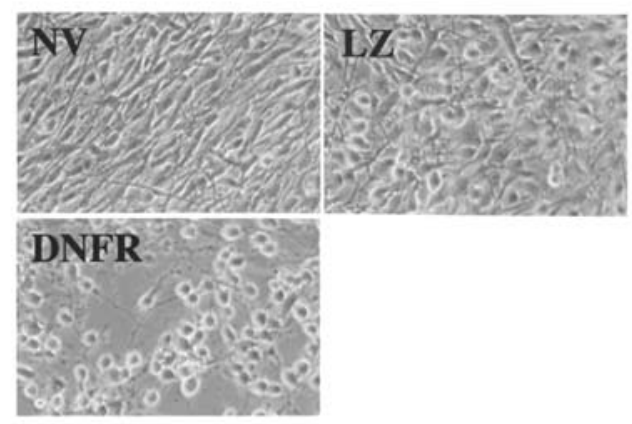

B

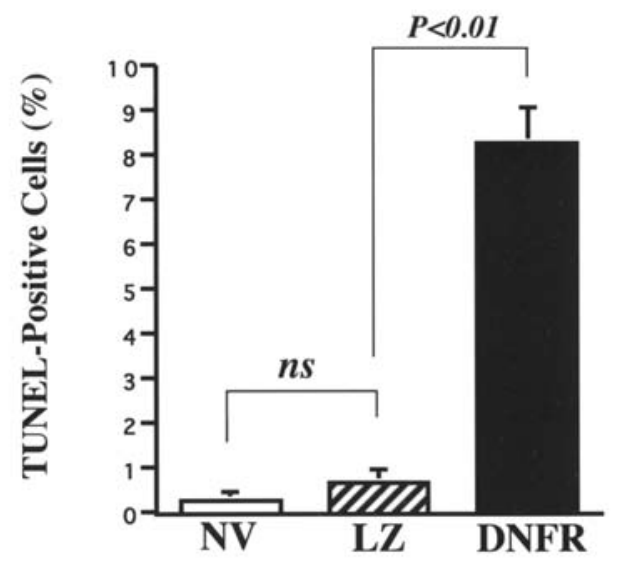

C

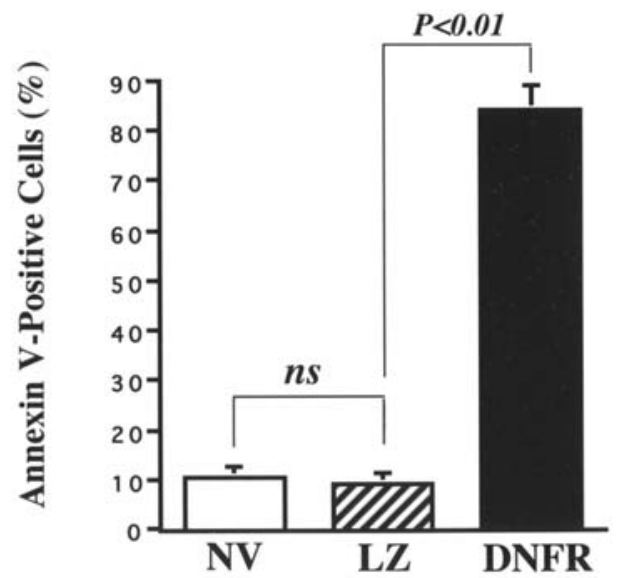

Figure 1. Apoptosis of U251MG cells induced by the blockade of endogenous FGF signaling. The cells were infected with 200 MOI of AdvLacZ (LZ), AdvDNFGFR (DNFR); otherwise, were mock-infected (NV). Morphology was observed by phase-contrast microscopy $48 \mathrm{~h}$ after the infection (A). Semi-quantitative analysis of apoptosis was performed with the TUNEL method (B) and flow cytometric annexin $\mathrm{V}$ assay $24 \mathrm{~h}$ after the infection (C). The percentages of TUNEL-positive or annexin V-positive cells are shown as the mean $\pm \mathrm{SD}(n=3)$. ns, not significant.

multiplicity of infection (MOI) of 200, which was determined by conventional plaque assay. Caspase-9 inhibitor (Z-LEHDFMK) and caspase-3 inhibitor (Z-DEVD-FMK) were purchased from MBL (Nagoya, Japan). Cells were pretreated with $50 \mu \mathrm{M}$ of these caspase inhibitors for $6 \mathrm{~h}$ prior to the infection with AdvDNFR.

Ultraviolet treatment. For UV treatments, the cells were exposed using a UV Stratalinker 1800 (Stratagene, La Jolla, CA) at $100 \mathrm{~J} / \mathrm{m}^{2}$ for $2 \mathrm{~min}(32)$. 

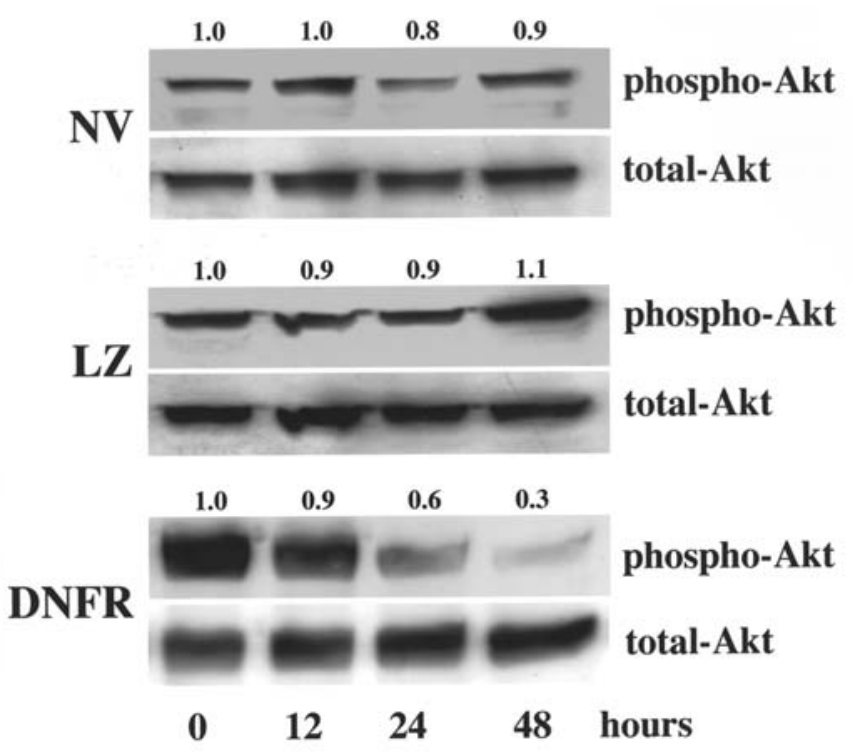

Figure 2. Influence of the blockade of endogenous FGF signaling on Akt activation in U251MG cells. The cells were infected with 200 MOI of AdvLacZ (LZ), AdvDNFGFR (DNFR); otherwise, were mock-infected (NV). The total cell lysates were extracted $24 \mathrm{~h}$ after the infection and subjected to immunoblotting. The membranes were first probed with phospho-Akt specific antibody (phosphor-Akt) and then re-probed with antibody for total Akt expression (total-Akt). The results are also expressed in relative densitometric units, with a value of 1.0 adopted for untreated cells.

Detection of apoptosis. For the detection of apoptotic cells with nuclear fragmentation, a terminal deoxynucleotidyl transferase (TdT)-mediated deoxyuridine triphosphate (dUTP) nick end-labeling (TUNEL) assay was performed by using an in situ cell death detection kit (Roche, Mannheim, Germany) $(13,14)$. The cells inoculated on a coverslip were fixed in $4 \%$ paraformaldehyde in PBS at room temperature for $30 \mathrm{~min}$, and permeated with $0.1 \%$ Triton $\mathrm{X}-100$ in $0.1 \%$ sodium citrate. Samples were incubated with TdT and fluorescein-labeled dUTP at $37^{\circ} \mathrm{C}$ for $1 \mathrm{~h}$, and then counterstained with propidium iodide (PI)

Apoptotic cells with fragmented nuclei were visualized under a fluorescence microscope (Leica, Wetzlar, Germany), and percentages of apoptotic cells were estimated by counting a total of 300 cells from random fields. A positive control was established by incubating the specimens in DNase I, RNase-free (Roche) for 10 min before the reaction with TdT enzyme (data not shown). Apoptotic cells were also measured using an Annexin V-EGFP apoptosis detection kit (MBL) following the manufacturer's instructions $(32,33)$. Both attached and detached cells were collected by trypsinization and centrifugation, and then resuspended with binding buffer, followed by incubation with annexin V-EGFP and propidium iodide (PI) for $5 \mathrm{~min}$ at room temperature. Cells were subjected to flow cytometry (FACScan; Becton Dickinson, San Jose, CA) $(E x=488 \mathrm{~nm}, E m=530 \mathrm{~nm})$ and analyzed using CellQuest software. Annexin V-positive cells were regarded as apoptotic cells.

Immunoblotting. Total cell extract was prepared by using Nonidet P (NP)-40 lysis buffer (150 mM NaCl, $50 \mathrm{mM}$
Tris-HCl, $\mathrm{pH} 8.0,1 \%$ NP-40). Protein concentration was determined by Bio-Rad protein assay reagent (Bio-Rad Laboratories, Hercules, CA). Proteins $(70 \mu \mathrm{g})$ were fractionated by SDS-polyacrylamide gel electrophoresis (SDS-PAGE) and then electrotransferred onto nitrocellulose membrane (Hybond ECL; Amersham Bioscience, Buckinghamshire $\mathrm{UK}$ ), followed by probing with a rabbit polyclonal antiphospho-Akt specific (Ser437) or total Akt, a rabbit polyclonal anti-PARP, a rabbit polyclonal anti-caspase-9, a rabbit polyclonal anti-caspase-3, or a mouse monoclonal anti-caspase- 8 (Cell Signaling Technology, Beverly, MA), respectively. Horseradish peroxidase (HRP)-labeled anti-rabbit or antimouse immunoglobulin was used for the detection of bound primary antibodies by enhanced chemiluminescence (Amersham Bioscience). Densitometric analysis was performed with NIH image software.

Statistical analysis. Experimental groups were compared by analysis of variance (ANOVA) and, when appropriate, by Student's t-test. All data are expressed as the mean \pm SD. A level of $\mathrm{p}<0.05$ was considered statistically significant.

\section{Results}

Apoptosis of U251MG cells was induced by the blockade of endogenous FGF signaling. Consistent with our previous results, infection with $200 \mathrm{MOI}$ of AdvDNFGFR resulted in marked apoptosis in U251MG cells $(14,15)$. At $24 \mathrm{~h}$ after the infection, phase-contrast microscopy revealed a loss of bipolar protrusion of glioma cells and an increase in the round apoptotic cells expressing DNFGFR. Infection with an equivalent dosage of AdvLacZ had minimal effects (Fig. 1A). The percentages of TUNEL-positive cells were $0.3 \%$ in mockinfected cells, $0.7 \%$ in AdvLacZ-infected cells, and $8.3 \%$ in AdvDNFGFR-infected cells ( $\mathrm{p}<0.01$, versus the control LacZ virus-infected cells) (Fig. 1B). Annexin V-positive cells were also counted and their percentages were $11.0 \%$ in mockinfected cells, 9.6\% in AdvLacZ-infected cells, and 84.6\% in AdvDNFGFR-infected cells $(\mathrm{p}<0.01$, against the control LacZ virus-infected cells) (Fig. 1C).

As the flow cytometric annexin $\mathrm{V}$ method is more sensitive for detecting the early stage of apoptosis than the TUNEL method, the following experiments were mainly carried out with annexin V staining. Annexin V-positive cells were $25 \%$ in $200 \mathrm{MOI}$ of AdvRasN17-infected cells and were $85.6 \%$ in duplicated infection of AdvDNFGFR and AdvRasN17. Compared with the single infection with AdvDNFGFR, no additional apoptotic effect was observed by simultaneous infection with AdvDNFGFR and AdvRasN17 (data not shown).

Down-regulation of Akt activation was induced by the blockade of autocrine FGF signaling. Activation of Akt (an increase in the ratio of phosphorylated Akt to total Akt) was confirmed by Western blotting, and AdvDNFGFR infection (MOI of 200) resulted in a $60 \%$ induction of the Akt activity at $24 \mathrm{~h}$ and a $30 \%$ induction at $48 \mathrm{~h}$ compared with the controls. On the other hand, no significant time-dependent change was observed in mock-infected or AdvLacZ-infected cells (Fig. 2). 
$\mathbf{A}$
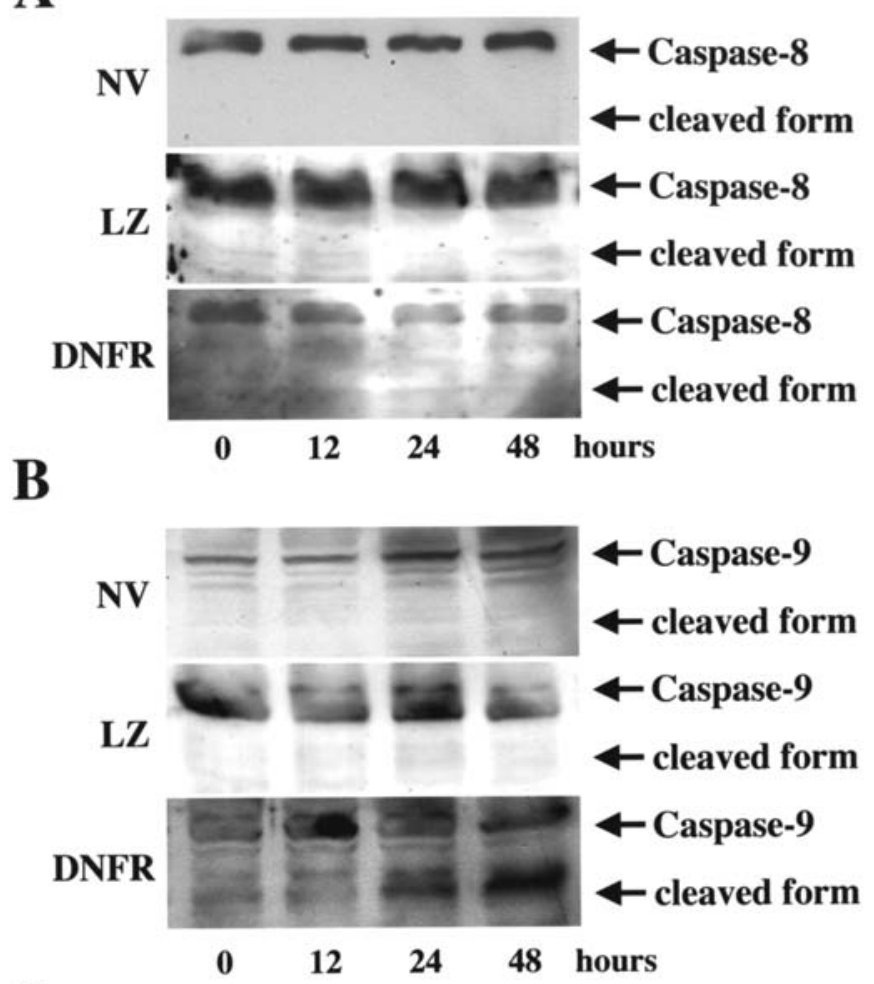

$\mathbf{C}$

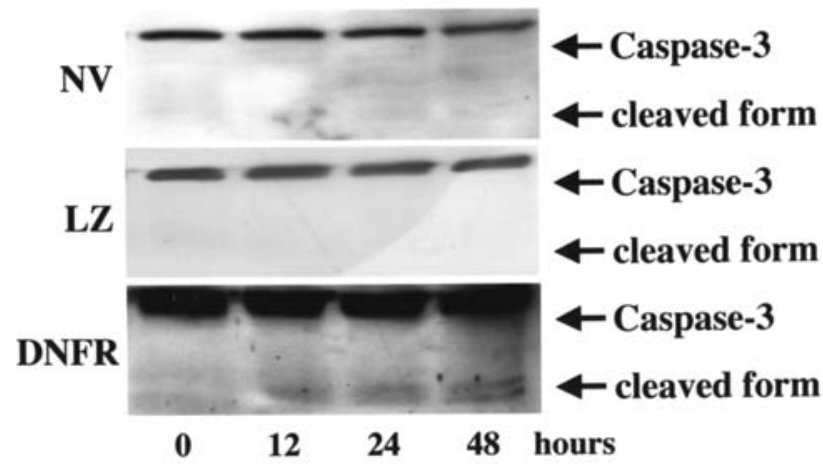

Figure 3. Activation of caspase- 9 and -3 , but not -8 , in U251MG cells by the blockade of endogenous FGF signaling. Total cell lysates were extracted at the time indicated after the infection with 200 MOI of AdvLacZ (LZ), AdvDNFGFR (DNFR), otherwise mock-infection (NV), and were then subjected to immunoblotting. The membranes were then probed with the antibody for caspase-8 (A), caspase-9 (B), or caspase-3 (C).

Activation of caspase-9 and -3 , and an increase in the cleaved form of PARP were induced by the blockade of autocrine $F G F$ signaling. Activation of caspases was estimated by their cleavage using immunoblotting $(32,33)$. AdvDNFGFR infection (MOI of 200) resulted in the cleavage of caspase-9 and -3 , but not -8 , in a time-dependent fashion (Fig. 3). The level of the cleaved form of PARP was also increased by the infection with AdvDNFGFR, and it was completely abolished by the pretreatment with caspase-9 inhibitor (Z-LEHDFMK) and caspase-3 inhibitor (Z-DEVD-FMK), respectively (Fig. 4).

UV radiation-induced apoptosis was associated with caspase- 8 activation. To examine the effect of different apoptotic stimuli on the caspase activation, UV radiation was performed. After

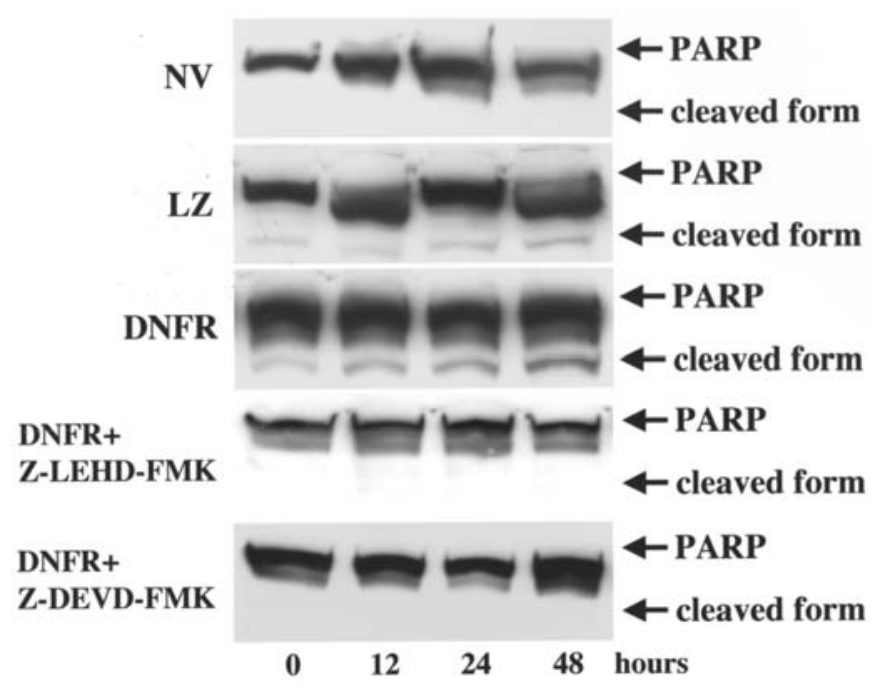

Figure 4. PARP cleavage induced by the blockade of endogenous FGF signaling through a caspase cascade. U251MG cells pre-incubated in the absence or the presence of caspase-9 inhibitor (Z-LEHD-FMK) or caspase-3 inhibitor (Z-DEVD-FMK) $(50 \mu \mathrm{M}$ each) were infected with $200 \mathrm{MOI}$ of AdvLacZ (LZ), AdvDNFGFR (DNFR); otherwise, were mock-infected (NV). Total cell lysates were extracted at each time indicated after the infection and subjected to immunoblotting. The membranes were then probed with a rabbit polyclonal anti-PARP antibody.

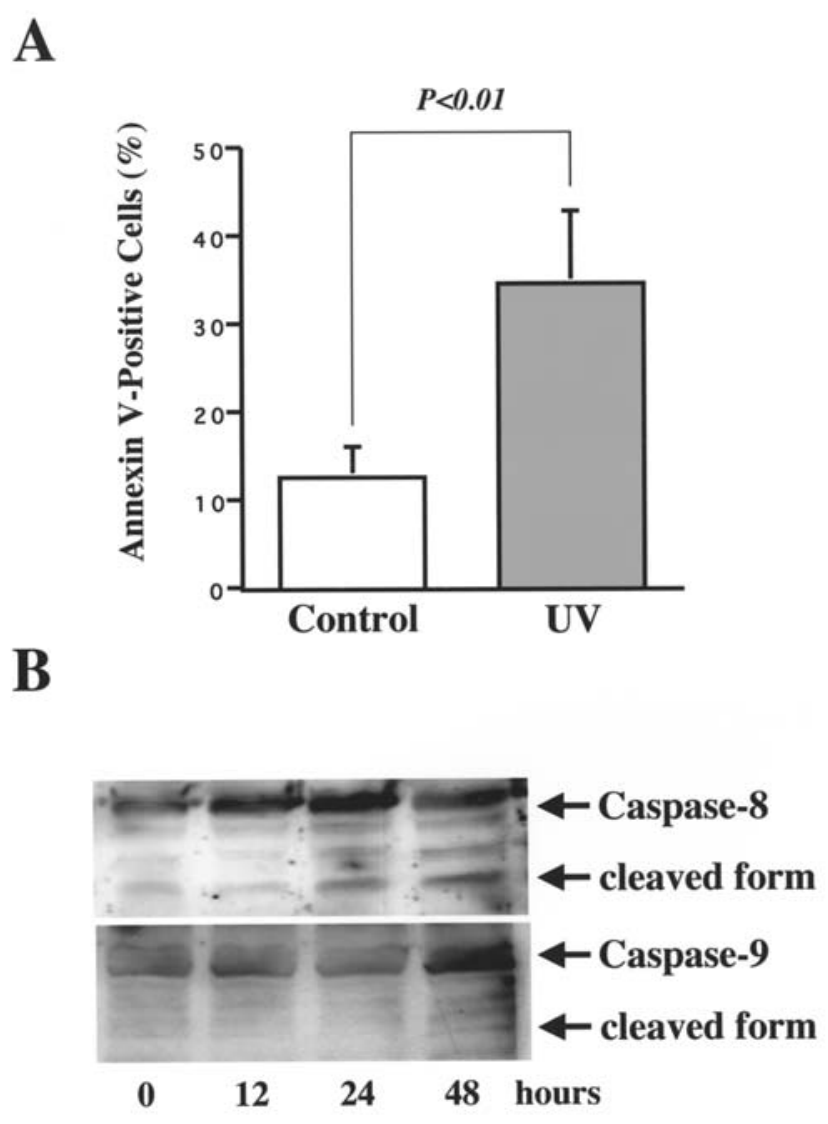

Figure 5. UV radiation-induced apoptosis in U251MG cells. The cells were exposed to UV $\left(100 \mathrm{~J} / \mathrm{m}^{2}\right)$. Semi-quantitative analysis of apoptosis was performed using a flow cytometric annexin $\mathrm{V}$ assay after $24 \mathrm{~h}$ (A). The percentages of annexin V-positive cells are shown as the mean $\pm \operatorname{SD}(n=3)$. Total cell lysates were also extracted at each indicated time after UV radiation, and were then subjected to immunoblotting (B). The membranes were probed with the antibody for caspase- 8 (upper panel) or caspase- 9 (lower panel). 
$24 \mathrm{~h}$ of $\mathrm{UV}$ radiation $\left(100 \mathrm{~J} / \mathrm{m}^{2}\right)$, annexin $\mathrm{V}$-positive cells made up $\sim 34.7 \%$ of AdvDNFGFR-infected cells ( $p<0.01$, versus the mock-irradiated cells). Since the preliminary experiments revealed that the percentages of apoptotic cells were not increased at the higher dose of irradiation (200-300 J/m²) (data not shown), caspase activity was measured under the condition of $100 \mathrm{~J} / \mathrm{m}^{2}$ of irradiation. In contrast to the AdvDNFGFR infection, the cleaved form of caspase-8, but not that of caspase-9, was increased in a time-dependent fashion (Fig. 5).

\section{Discussion}

In the present study, we showed that the inhibition of endogenous FGF signaling by forced expression of dominant negative FGFR resulted in marked apoptosis in human glioma cells, in association with: 1) down-regulation of Akt phosphorylation; 2) activation of caspase-9 and -3; and 3) cleavage of PARP. PARP cleavage was completely abolished by the pretreatment with caspase-9 inhibitor (Z-LEHD-FMK) and caspase- 3 inhibitor (Z-DEVD-FMK). In turn, UV radiation induced activation of caspase- 8 , but not -9 , in these cells. Our data suggest that the induction of apoptosis via inhibition of endogenous FGF signaling is dependent on the caspase-9 pathway.

Autocrine FGF signaling facilitates cell survival activity of human glioma cells (3-15). Inhibition of endogenous FGF signaling may have promise as a potent therapeutic manipulation to suppress the excess growth of tumor cells. We have reported that antisense inhibition of endogenous bFGF shows minimal effect on the induction of apoptosis (13). On the other hand, both our previous data and our present findings clearly showed that marked apoptosis was induced by the overexpression of dominant negative FGFR in human glioma cells via the down-regulation of Akt activity (14, Figs. 1 and 2). Thus, the cell-survival activity was thought to be largely dependent on the receptor-mediated pathway.

Overexpression of a dominant negative mutant of Ras resulted in approximately one-third to one-fourth degree of apoptosis, compared with the expression of dominant negative FGFR. No additional apoptotic induction was seen in the cells expressing both dominant negative Ras and dominant negative FGFR (data not shown). As we have already shown that wortmannin (a PI3K inhibitor) effectively inhibits Akt activation and induces apoptosis (15), these findings may further support the notion that the pathway mediated by Ras and PI3K/Akt plays important roles in preventing apoptosis in human glioma cells. In this context, we subsequently tried to find a key molecule responsible for the apoptotic signaling in the downstream of FGFR and Akt, focusing on the caspases.

In the present study, the percentage of apoptotic cells was much higher in the observation using annexin $\mathrm{V}$ staining than in that using the TUNEL method (Fig. 1). Annexin V can stably bind to the membrane phospholipid phosphatidylserine translocated from the inner face of the plasma membrane to the cell surface soon after the initiation of apoptosis $(34,35)$. Thus, annexin V staining is more sensitive for detecting the early phase of apoptosis. In contrast, the TUNEL method allows detection of the DNA strand breaks, which means detecting the final phase of apoptosis $(36,37)$.
Apoptosis induced by the blockade of endogenous FGF signaling was associated with activation of caspase-9, but not -8 , and the former activation appeared to lead to activation of an effector caspase, caspase-3 (Fig. 3). Caspase activation was coordinately observed with cleavage of PARP. Both the caspase-9 inhibitor (Z-LEHD-FMK) and the caspase-3 inhibitor (Z-DEVD-FMK) inhibited apoptosis induced by the blockade of endogenous FGF signaling by $~ 50 \%$ (data not shown), in association with abolished PARP degradation (Fig. 4). Thus, the caspase-9-dependent activation of caspase-3 may act as an executioner of apoptosis in human glioma cells by inhibiting their autocrine FGF signaling.

The caspase- 8 and -9 pathways share distinct sets of apoptotic signals. The former is involved in death receptormediated apoptosis such as those triggered by Fas, TNF (tumor necrosis factor), and TRAIL (TNF-related apoptosisinducing ligand). The latter is initiated by cytochrome c release from mitochondria, and leads to the complex formation of apoptosome with Apaf-1 $(21,23,24)$. It has been reported that Akt phosphorylates procaspase-9 at Ser-196 (27), rendering it resistant to processing and activation. Thus, it could be anticipated that sustained activation of Akt downstream of FGFR continues to suppress caspase-9 activation in human glioma cells. However, Akt plays numerous roles in the cells, not only preventing apoptosis but also promoting cell cycle progression and migration or invasion (20). For example, oncogene $\mathrm{Mdm} 2$ is a direct target of Akt, which is an important regulator of p53, a tumor suppressor gene product that is involved in cell cycle regulation and apoptosis $(38,39)$. Akt has been shown to regulate cyclindependent kinase inhibitors such as p21Waf-1 and p27Kip-1, directly or indirectly, which also display a profound influence on the cell survival activity $(20,40)$. Thus, further studies will be needed to clarify the anti-apoptotic pathway mediated by endogenous FGF signaling via Akt.

Although the blockade of endogenous FGF signaling did not induce caspase- 8 activation in the present study, we observed weak induction of caspase- 8 by UV radiation (Fig. 5). It has been reported that a different form of DNA damage, $\gamma$-irradiation, initiates the caspase-9 pathway leading to the apoptosis in human glioma cells, in association with the up-regulation of Apaf-1 (41). On the other hand, UV irradiation induces apoptosis in embryonic stem cells derived from caspase-9 knockout mice, suggesting a caspase-8-dependent pathway (42). Although caspase-8 (extrinsic; death receptormediated) and caspase-9 (intrinsic; mitochondrial, stressinduced) have distinct apoptotic pathways $(23,24)$, the mitochondrial cytochrome c-dependent pathway may be activated by caspase- 8 , independently of the interaction with the Fasassociated death domain (FADD) or the formation of the death-inducing signal complex (DISC) (43).

Consistent with our results, UV-induced apoptosis has been shown to be mediated by activation of caspase- 8 , but not -9 , in the human breast cancer cell line MCF-7 (44). Comparing with the blockade of the endogenous FGF signaling, the induction of UV-induced apoptosis was weakly observed with mild activation of caspase-8 (Figs. 1 and 3 vs. Fig. 5). It has been reported that the expression of caspase- 8 is low in the human glioma cell lines U251MG and U-373MG (45), and many resected glioma samples lack a detectable level 
of caspase-8 (46). Thus, apoptotic signaling via caspase-9 activation may be a more potent target for the development of a molecular-based approach to improve the prognosis of human gliomas, which could be induced by the blockade of endogenous FGF signaling.

\section{Acknowledgements}

We are grateful to Dr Joseph Nevins (Duke University, Durham, NC) and Dr J.M. Wilson (University of Pennsylvania, Philadelphia, PA) for provision of the materials used for the viral constructs. We also thank Dr Hirohisa Yano (Department of Pathology, Kurume University, Japan) for his help with the flow cytometric analysis, and Dr Nobuyuki Arima (Kumamoto City Hospital, Kumamoto, Japan) and Dr Koichi Oshima (Department of Pathology, Kurume University, Japan) for their helpful remarks.

\section{References}

1. Blank P: Management of malignant glioma: role of surgery in relation to multimodality therapy. J Neurovirol 4: 227-236, 1998.

2. Furnari FB, Huang HJ and Cavenee WK: Genetics and malignant progression of human brain tumors. Cancer Surv 25: 233-275, 1995.

3. Takahashi JA, Mori H, Fukumoto M, Igarashi K, Jaya M, Oda Y, Kikuchi $\mathrm{H}$ and Hatanaka M: Gene expression of fibroblast growth factors in human gliomas and meningiomas: Demonstration of cellular source of basic fibroblast growth factor mRNA and peptide in tumor tissues. Proc Natl Acad Sci USA 87: 5710-5714, 1990.

4. Morrison RS, Yamaguchi F, Saya H, Bruner JM, Yahanda AM, Donehower LA and Berger M: Basic fibroblast growth factor and fibroblast growth factor receptor I are implicated in the growth of human astrocytomas. J Neurooncol 18: 207-216, 1994.

5. Miyagi N, Kato S, Terasaki M, Shigemori M and Morimatsu M: Fibroblast growth factor- 2 and -9 regulate proliferation and production of matrix metalloproteinases in human gliomas. Int $\mathbf{J}$ Oncol 12: 1085-1090, 1998.

6. Takahashi JA, Fukumoto M, Kozai Y, Ito N, Oda Y, Kikuchi H and Hatanaka M: Inhibition of cell growth and tumorigenesis of human glioblastoma cells by a neutralizing antibody against human basic fibroblast growth factor. FEBS Lett 288: 65-71, 1991.

7. Murphy PR, Sato Y and Knee RS: Phosphorothioate antisense oligonucleotides against basic fibroblast growth factor inhibit anchorage-dependent and anchorage-independent growth of a malignant glioblastoma cell line. Mol Endocrinol 6: 877-884, 1992.

8. Murai N, Ueba T, Takahashi JA, Yang HQ, Kikuchi H, Hiai H, Hatanaka $\mathbf{M}$ and Fukumoto $\mathbf{M}$ : Apoptosis of human glioma cells in vitro and in vivo induced by a neutralizing antibody against basic fibroblast growth factor. J Neurosurg 85: 1072-1077, 1996.

9. Middaugh CR, Mach H, Burke CJ, Volkin DB, Dabora JM, Tsai PK, Bruner MW, Ryan JA and Marfia KE: Nature of the interaction of growth factors with suramin. Biochemistry 31 : 9016-9024, 1992.

10. Cuevas P, Reimers D, Diaz D, Lozano RM and Gimenez-Gallego G: Apoptosis of glioma cells induced by the fibroblast growth factor inhibitor 1,3,6-naphthalenetrisulfonate. Neurosci Lett 275: 149-151, 1999.

11. Redekop GJ and Naus CC: Transfection with bFGF sense and antisense cDNA resulting in modification of malignant glioma growth. J Neurosurg 82: 83-90, 1995.

12. Yamada SM, Yamaguchi F, Brown R, Berger MS and Morrison RS: Suppression of glioblastoma cell growth following antisense oligonucleotide-mediated inhibition of fibroblast growth factor receptor expression. Glia 28: 66-76, 1999.

13. Aoki T, Kato S, Fox JC, Okamoto K, Sakata K, Morimatsu M and Shigemori M: Inhibition of autocrine fibroblast growth factor signaling by the adenovirus-mediated expression of an antisense transgene or a dominant negative receptor in human glioma cells in vitro. Int J Oncol 21: 629-636, 2002.
14. Sakata K, Kato S, Fox JC, Shigemori M and Morimatsu M: Autocrine signaling through Ras regulates cell survival activity in human glioma cells: potential cross-talk between Ras and the phosphatidylinositol 3-kinase-Akt pathway. J Neuropathol Exp Neurol 61: 975-983, 2002.

15. Kono K, Ueba T, Takahashi JA, Murai N, Hashimoto N, Myoumoto $\mathrm{A}$, Itoh $\mathrm{N}$ and Fukumoto $\mathrm{M}$ : In vitro growth suppression of human glioma cells by a 16-mer oligopeptide: a potential new treatment modality for malignant glioma. J Neurooncol 163: 163-171, 2003.

16. Jaya M, Schlessinger J and Dionne CA: Fibroblast growth factor receptor tyrosine kinases: molecular analysis and signal transduction. Biochim Biophys Acta 1135: 185-199, 1995.

17. Marshall MS: Ras target proteins in eukaryotic cells. FASEB 9: 1311-1318, 1995

18. Kouhara H, Hadari YR, Spivak-Kroizman T, Schilling J, Bar-Sagi D, Lax I and Schlessinger J: A lipid-anchored Grb2binding protein that links FGF-receptor activation to the Ras/ MAPK signaling pathway. Cell 89: 693-702, 1997.

19. Ong SH, Hadari YR, Gotoh N, Guy GR, Schlessinger J and Lax I: Stimulation of phosphatidylinositol 3-kinase by fibroblast growth factor receptors is mediated by coordinated recruitment of multiple docking proteins. Proc Natl Acad Sci USA 98: 6074-6079, 2001

20. Datta SR, Brunet A and Greenberg ME: Cellular survival: a play in three Akts. Genes Dev 13: 2905-2927, 1999.

21. Ho PK and Hawkins CJ: Mammalian initiator apoptotic caspases. FEBS J 272: 5436-5453, 2005.

22. Decker P and Muller S: Modulating poly (ADP-ribose) polymerase activity: potential for the prevention and therapy of pathogenic situations involving DNA damage and oxidative stress. Curr Pharm Biotechnol 3: 275-283, 2002.

23. Bratton SB, MacFarlane M, Cain K and Cohen GM: Protein complexes activate distinct caspase cascades in death receptor and stress-induced apoptosis. Exp Cell Res 256: 27-33, 2000.

24. Sun XM, MacFarlane M, Zhuang J, Wolf BB, Green DR and Cohen GM: Distinct caspase cascades are initiated in receptormediated and chemical-induced apoptosis. J Biol Chem 274: 5053-5060, 1999

25. Datta SR, Dudek H, Tao X, Masters S, Fu H, Gotoh Y and Greenberg ME: Akt phosphorylation of BAD couples survival signals to the cell-intrinsic death machinery. Cell 91: 231-241, 1997.

26. Burnet A, Bonni A, Zigmond MJ, Lin MZ, Juo P, Hu LS, Anderson MJ, Arden KC, Blenis J and Greenberg ME: Akt promotes cell survival by phosphorylating and inhibiting a Forkhead transcription factor. Cell 96: 857-868, 1999.

27. Cardone MH, Roy N, Stennicke HR, Salvesen GS, Franke TF, Stanbridge E, Frisch S and Reed JC: Regulation of cell death protease caspase-9 by phosphorylation. Science 282: 1318-1321, 1998.

28. Miyamoto T, Leconte I, Swain JL and Fox JC: Autocrine FGF signaling is required for vascular smooth muscle cell survival in vitro. J Cell Physiol 177: 58-67, 1998

29. Leone G, DeGregori J, Sears R, Jokoi L and Nevins JR: Myc and Ras collaborate in inducing accumulation of active cyclin E/Cdk2 and E2F. Nature 387: 422-426, 1997.

30. Yang Y, Raper SE, Cohn JA, Engelhardt JF and Wilson JM: An approach for treating the hepatobiliary disease of cystic fibrosis by somatic gene transfer. Proc Natl Acad Sci USA 90: 4601-4605, 1993.

31. Kozarsky KF and Wilson JM: Gene therapy: adenovirus vectors. Curr Opin Genet Dev 3: 499-503, 1993.

32. Izumaru S, Arima N, Toyozumi Y, Kato S, Morimatsu M and Nakashima T: Down-regulation of $\mathrm{p} 21 \mathrm{Waf}-1$ protein facilitates IR- and UV-induced apoptosis in human squamous carcinoma cells. Int J Oncol 24: 1245-1255, 2004.

33. Toyozumi Y, Arima N, Izumaru S, Kato S, Morimatsu M and Nakashima T: Loss of caspase- 8 activation pathway is a possible mechanism for CDDP resistance in human laryngeal squamous cell carcinoma, HEp-2 cells. Int J Oncol 25: 721-728, 2004.

34. Koopman G, Reutelingsperger CP, Kuijten GA, Keehnen RM, Pals ST and van Oers MH: Annexin V for flow cytometric detection of phosphatidylserine expression on $\mathrm{B}$ cells undergoing apoptosis. Blood 84: 1415-1420, 1994

35. Vermes I, Haanen C, Steffens-Nakken H and Reutelingsperger C: A novel assay for apoptosis. Flow cytometric detection of phosphatidylserine expression on early apoptotic cells using fluorescein labelled Annexin V. J Immunol Methods 184: 39-51, 1995. 
36. Gavrieli Y, Sherman Y and Ben-Sasson SA: Identification of programmed cell death in situ via specific labeling of nuclear DNA fragmentation. J Cell Biol 119: 493-501, 1992.

37. Gold R, Schmied M, Rothe G, Zischler H, Breitschopf H, Wekerle $\mathrm{H}$ and Lassmann H: Detection of DNA fragmentation in apoptosis: application of in situ nick translation to cell culture systems and tissue sections. J Histochem Cytochem 41: 1023-1030, 1993.

38. Mayo LD and Donner DB: A phosphatidylinositol 3-kinase/Akt pathway promotes translocation of Mdm2 from the cytoplasm to the nucleus. Proc Natl Acad Sci USA 98: 11598-11603, 2001.

39. Levine AJ: p53, the cellular gatekeeper for growth and division. Cell 88: 323-331, 1997.

40. Coqueret O: New roles for p21 and p27 cell-cycle inhibitors: a function for each cell compartment? Trends Cell Biol 13: 65-70, 2003.

41. Yanamandra N, Kondraganti S, Srinivasula SM, Gujrati M, Olivero WC, Dinh DH and Rao JS: Activation of caspase-9 with irradiation inhibits invasion and angiogenesis in SNB19 human glioma cells. Oncogene 23: 2339-2346, 2004.
42. Hakem R, Hakem A, Duncan GS, Henderson JT, Woo M, Soengas MS, Elia A, de la Pompa JL, Kagi D, Khoo W, Potter J, Yoshida R, Kaufman SA, Lowe SW, Penninger JM and Mak TW: Differential requirement for caspase 9 in apoptotic pathways in vivo. Cell 94: 339-352, 1998.

43. Fan TJ, Han LH, Cong RS and Liang J: Caspase family proteases and apoptosis. Acta Biochim Biophys Sin 37: 719-727, 2005.

44. Ferguson HA, Marietta PM and Van Den Berg CL: UV-induced apoptosis is mediated independent of caspase-9 in MCF-7 cells: a model for cytochrome c resistance. J Biol Chem 278: 45793-45800, 2003

45. Shinoura N, Yamamoto N, Yoshida Y, Asai A, Kirino T and Hamada H: Adenovirus-mediated transfer of caspase-8 in combination with superrepressor of NF-kappaB drastically induced apoptosis in gliomas. Biochem Biophys Res Commun 271: 544-552, 2000.

46. Ashley DM, Riffkin CD, Muscat AM, Knight MJ, Kaye AH, Novak U and Hawkins CJ: Caspase- 8 is absent or low in many ex vivo gliomas. Cancer 104: 1487-1496, 2005. 